\title{
Teacher responsibility over intended, taught, and tested curriculum, and its association with students' science performance in PISA 20 I 5 across Didaktik and curriculum countries
}

\author{
Armend Tahirsylaj
}

\section{Introduction}

Various foci of curricula affect modern-day schooling. Educational authorities design formal curricula to structure educational experiences for students. However, students are not exposed only to formal curricula within bounded school settings but also to other unofficial curricula that shape what students learn in and out of schools. Schubert (2008) elucidated eight formats of curricula that influence schooling directly and/or indirectly, namely, (1) intended which means the specific education goals as defined by the formal schooling institutions - most often by a central or local government; (2) taught - which means the actual curriculum that teachers cover in their day-to-day teaching in classroom settings; (3) experienced - which implies thoughts, meanings, and feelings of students as they encounter the curriculum delivered to them by teachers; (4) embodied - primarily meaning the curriculum that students 'take with them' beyond what is measured by grades and test scores; (5) hidden capturing the education that is conveyed to students by school structures that are not part of the official/formal/intended curriculum. The sources for the hidden curriculum might include race, class, gender, culture, ethnicity, language, religion, and so on; (6) tested - which captures what gets tested in the school settings and why, and who benefits from testing; (7) null - which is referred to as the curriculum that does not get tested and is not usually represented in tests, such as capacities for art, philosophy, psychology, imagination, and lifelong learning to name a few; and (8) outside curriculum - which covers the out-of-school curricula that students are exposed to through their contexts of culture, community, language, families, mass media, the internet, and so on.

Teachers, meanwhile, from the triangle of teachers, students, and content in the Didaktik tradition, facilitate students' access to specific subject content/ 
curriculum. This chapter explores the extent to which teachers are responsible for three of the eight curricula aspects, namely intended, taught, and tested curriculum. Regarding teacher responsibility, the study relies on the definition provided in OECD's (2009) assessment framework, where teacher responsibility was taken to mean responsibility over decisions pertaining to school management, financial issues, and instructional issues. Further, the study utilises the definition of Corcoran (1995) on teacher responsibility as teachers' capacity to make curriculum- and assessment-related decisions. As conceived here, teacher responsibility is different from teacher autonomy, which has been defined along professional, faculty/staff, and individual dimensions (Frostenson, 2012), or as having an institutional dimension, implying collective autonomy of the teaching profession, and a service dimension, concerning individual teacher autonomy at classroom level and school level practices more broadly (Wermke and Höstfält, 2014).

To achieve its goals, the study uses Programme for International Student Assessment (PISA) data to examine variation of teacher responsibility over intended, taught, and tested curriculum in different contexts, and also to explore whether teacher responsibility over these three curriculum foci matters for student science performance in PISA 2015. The study addresses two main research questions: (1) do teachers have a say on intended, taught, and tested curriculum across Didaktik and curriculum countries? and (2) what is the association of teacher responsibility over intended, taught, and test curriculum with student science performance in PISA 2015 across six Didaktik (Denmark, Finland, Norway, Sweden, Austria, and Germany) and six curriculum (Australia, Canada, Ireland, New Zealand, United Kingdom, and the United States) countries? The purpose of the study is first to empirically test claims made about teachers' responsibility across Didaktik and curriculum traditions, and second to further contribute to the field of comparative curriculum studies employing education frameworks and quantitative approaches, as a new method to address curriculum/Didaktik issues in the twenty-first century. The study builds on author's prior work (Tahirsylaj, 2019) to expand the range of data used to test theoretical claims put forth over similarities and differences between curriculum and Didaktik traditions.

\section{Theoretical framework}

Curriculum and Didaktik serve as two main education traditions in the Western world that shape to a large extent, for example, what education policies are implemented in school systems (Hopmann, 2015; Tahirsylaj, Niebert and Duschl, 2015) and how teachers are educated and trained (Tahirsylaj, Brezicha and Ikoma, 2015). Curriculum and Didaktik frameworks claim, amongst else, that there is a higher level of teacher responsibility among teachers working in Didaktik than those in curriculum countries (Westbury, 2000). While there 
are four competing ideologies that constitute the field of curriculum studies, including scholar academic, social efficiency, learner centred, and social reconstruction (Schiro, 2013), the social efficiency model was dominant throughout the twentieth century up the present day (Tahirsylaj, 2017; Deng and Luke, 2008; Kliebard, 2004; Westbury, 2000). Didaktik, on the other hand, developed as a theory of teaching and learning in continental Europe, dealing with issues of order, sequence, and choice (Hopmann, 2007) and a tradition "as a relation between teachers and learners (the who), subject matter (the what) and instructional methods (the how)" (Klette, 2007, p. 147). While both traditions have experienced revisions and modifications as a result of global education trends since the early 2000s, they still operate under their own original assumptions, meaning Didaktik is still more teacher oriented and content focused, while curriculum is methods oriented and assessment intensive (Tahirsylaj, Niebert and Duschl, 2015).

The study follows a logic of rationale where the constructs of interest pertaining to intended, taught, and tested curricula are thought to be mediated by the instructional system in place in corresponding countries representing curriculum and Didaktik traditions, which in turn affect the student's test score in PISA assessment, while controlling for a number of student- and school-level variables. In this vein and in line with the first research question and curriculum/Didaktik framework, the hypothesis is that teachers in Didaktik traditions have stronger say regarding their responsibility over intended, taught, and tested curriculum than their counterparts in curriculum traditions. The second research question is exploratory in nature, however based on prior work (Tahirsylaj, 2019) it can be hypothesised that the three variables of interest used as proxies for intended, taught, and tested curricula will not show strong associations with students' science performance in PISA 2015 across both curriculum and Didaktik tradition countries in the sample.

\section{Methodology}

This study employs an innovative quantitative approach to address the two main research question. It utilises PISA 2015 data made available by the Organisation for Economic Cooperation and Development (OECD). The PISA test has been administered every three years since 2000. PISA tests 15-year students' skills in three cognitive domains, including mathematics, science, and reading. To address the first research question, the study employs descriptive analysis to examine variation in teacher responsibility on intended, taught, and tested curriculum across Didaktik and curriculum countries. Two-sample difference of proportion test for teacher responsibility over intended, taught, and tested curriculum is used, while case-wise deletion is applied to address missing data. To address the second research question, a hierarchical linear modelling (HLM) 
procedure will be used to explore the association of teacher responsibility measures over three foci of curricula on students' science performance in PISA 2015, while controlling for a number of student-level (socio-economic status (SES), gender, age, grade, and immigration status) and school-level (school type - public vs. private) variables. Mean substitution and dummy adjustment are applied as methods to address missing data.

HLM is a useful method for this study considering that PISA datasets have a nested structure of data with students nested in schools and schools nested in regions and/or countries, which arguably provides more precise estimates given that data structure (Raudenbush and Bryk, 2002). HLM is preferred over simple ordinary least square (OLS) method, since the latter assumes independence of observations which is rather misleading in nested data where variance within group tends to remain dependent.

To develop the HLM models, first an unconditional model was run for each country using the dependent variable. Here is the specified equation for science achievement.

$$
\text { science }_{i j}=\beta_{0 j}+e_{i j}
$$

Each school's intercept, $\beta_{0 j}$, is then set equal to a grand mean, $\gamma_{00}$, and a random error $u_{0 j}$,

$$
\beta_{0 j}=g_{00}+u_{0 j}
$$

where $j$ represents schools and $i$ represents students with a given country.

Substituting (2) into (1) produces

$$
\text { science }_{i j}=g_{00}+u_{0 j}+e_{i j}
$$

where:

$$
\begin{aligned}
& \beta_{0 j}=\text { mean science achievement for school } j \\
& g_{00}=\text { grand mean for science achievement } \\
& \operatorname{Var}\left(e_{i j}\right)=\theta=\text { within school variance in science achievement } \\
& \operatorname{Var}\left(u_{0 j}\right)=t_{00}=\text { between school variance in science achievement }
\end{aligned}
$$

This model explains whether there is variation in student's standardised science scores across $j$ schools for the given country. From here, a linear randomintercept model with covariates was set up. This model is an example of a linear mixed effects model that splits the total residual or error into two error components. It starts with a multiple-regression model, as follows:

$$
\text { Science scores }_{i j}=\beta_{1}+\beta_{2 j} x_{2 i j}+\ldots+\beta_{p} x_{p i j}+\xi_{i j}
$$


Here $\beta_{1}$ is the constant for the model, while $\beta_{2 j} x_{2 i j}$ to $\beta_{p} x_{p i j}$ represent covariates included in the given model. $\xi_{i j}$ is the total residual that is split into two error components:

$$
\xi_{i j} \Xi u_{j}+e_{i j}
$$

where $u_{j}$ is a school-specific error component representing the combined effects of omitted school characteristics or unobserved heterogeneity. It is a random intercept or the level 2 residual that remains constant across students, while level 1 residual $e_{i j}$ is a student-specific error component which varies across students $i$ as well as schools $j$. Substituting $\xi_{i j}$ into the multiplelinear regression model (4), we obtain the linear random-intercept model with covariates

$$
\text { Science scores }_{i j}=\beta_{1}+\beta_{2 j} x_{2 i j}+\ldots+\beta_{p} x_{p i j}+u_{j}+e_{i j}
$$

Again, $\beta_{2 j} x_{2 i j}$ to $\beta_{p} x_{p i j}$ represent the covariates included in the model, and they vary depending on how many covariates are included in a specific model. The final model focuses on three level 2 covariates representing teacher responsibility items - whether teachers were responsible for course content, choosing which textbooks are used, and establishing student assessment policies - and it also includes one school-level covariate of school type (public vs. private) and a number of student level 1 covariates, including SES, age, grade, immigration status (native vs. first generation vs. second generation), test language (native vs. another), and a dummy variable for gender, where female $=1$ and male $=0$, and controlling for dummy missing variables. The same full model is then run for each of the 12 countries in the study.

Teacher responsibility (TR) over intended, taught, and tested curriculum is measured in PISA 2015 by a question that asks school principals "Regarding your school, who has a considerable responsibility for the following tasks?" where principals had to select whether principals, teachers, school board, regional education authority, or national education authority decided about the following (coded 1 if teachers made the decision and 0 otherwise):

1 Deciding course content (a proxy for TR over intended curriculum)

2 Choosing which textbooks are used (a proxy for TR over taught curriculum, assuming textbooks extensively guide what teachers teach)

3 Establishing student assessment policies (a proxy for TR over tested curriculum, especially in terms of how the tested curriculum gets tested)

While it is acknowledged that school principals might be biased towards overreporting teachers' responsibilities that bias cannot be tested here because PISA 2015 collected data on these three variables from school principals only. The possibility that school principals might understand concepts related to the three 
variables differently constitutes another noise in the data that should serve as a caution in results' interpretation.

Four criteria - historical, cultural, empirical, and practical - as developed by Tahirsylaj (2019) are used to designate the 12 countries into respective Didaktik and curriculum groupings. In brief, the historical criterion relates to historical initiation and development of Didaktik tradition within Germanspeaking contexts in continental Europe, which then spread to the rest of continental and northern Europe, while curriculum tradition emerged in the UK and then spread to the rest of the English-speaking countries. The cultural aspect is borrowed from prior studies on world cultures, and more specifically Global Leadership and Organizational Behaviour Effectiveness Research Project (GLOBE), which grouped world countries into ten cultural clusters based on data from the surveys aimed at understanding organisational behaviour in respective societies (House et al., 2004). For example, the GLOBE project distinguishes between Anglo cluster, Germanic cluster, and Nordic cluster that are represented in the sample of the present study. The empirical criterion relies on empirical evidence from educational studies that examined whether the ten culture clusters could explain differences in students' performance in respective clusters (Zhang, Khan and Tahirsylaj, 2015). The practical element pertains to the first Didaktik-curriculum dialogue that took place during the 1990s, when two groups of scholars were involved - scholars and researchers representing Didaktik that included both German and Nordic scholars and, on the other hand, curriculum experts that included scholars mainly from the UK and US (Gundem and Hopmann, 1998).

\section{Results and findings}

Prior research exploring teacher responsibility across curriculum and Didaktik countries with PISA 2009 data (Tahirsylaj, 2019) showed that teachers across all 12 respective curriculum and Didaktik countries were reported to be highly responsible for issues related to course content, textbooks, and assessment policies. This study extends and expands prior work by examining the more recent dataset of PISA 2015. Results pertaining to the first research question on variation across Didaktik and curriculum countries over intended, taught, and tested curricula are presented in Figures 11.1 through 11.3. Figures are colour-coded and the black bar shows OECD average. The light grey bars show proportions for curriculum countries, while dark grey bars show results for Didaktik countries. Across the countries, there is a wide variation, and countries are spread over a continuum, while the two-sample difference of proportion test showed in all three measures that proportions were higher and statistically significant in Didaktik than in the curriculum sample overall.

Figure 11.1 shows the proportions of schools where teachers are reported to be responsible for course content in respective countries. As per curriculumDidaktik framework, the hypothesis was that more schools report teachers to 


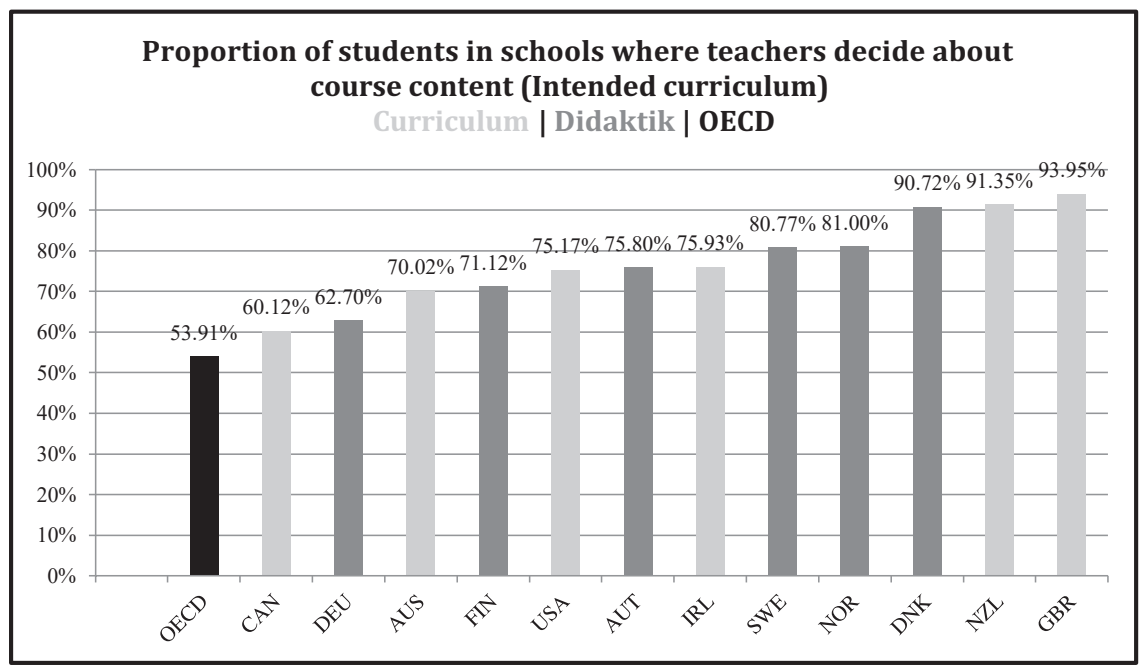

Figure II.I Intended curriculum (teacher responsibility over course content) Source: OECD PISA 2015 Datasets

be responsible in Didaktik than in curriculum countries. The graph shows that United Kingdom (93.95 per cent) and New Zealand (91.35 per cent) have the highest proportion of schools where teachers are responsible for course content. Canada has the lowest proportion of schools that have teachers who are responsible for course content, as reported by school principals, with 60.12 per cent. All countries in the sample are above the OECD average of 53.91 per cent. No clear separation is observed between curriculum and Didaktik countries. A difference-of-proportion test between Didaktik and curriculum countries produced a $\mathrm{z}$ statistic was $\mathrm{z}=4.02, p<0.001$, indicating that the difference between the two groups was statistically significant, and the mean was higher for Didaktik than curriculum countries.

Figure 11.2 shows the proportion of schools with teachers reported to be responsible for deciding about textbooks used in their respective countries. Overall, the proportions are quite high and above 70 per cent for all countries, and all countries are above the OECD average of 65.56 per cent. In Finland, the United Kingdom, and Sweden, close to 100 per cent of schools are reported to have teachers who decide about textbooks to be used. The proportion-of-differences test showed that the mean was higher for Didaktik than curriculum countries, and $z$ statistic $z=6.33, p>0.001$ indicated that the difference in proportions between the two groups was statistically significant. The results are in line with the original hypothesis that teacher responsibility is higher in schools in Didaktik than curriculum countries. 


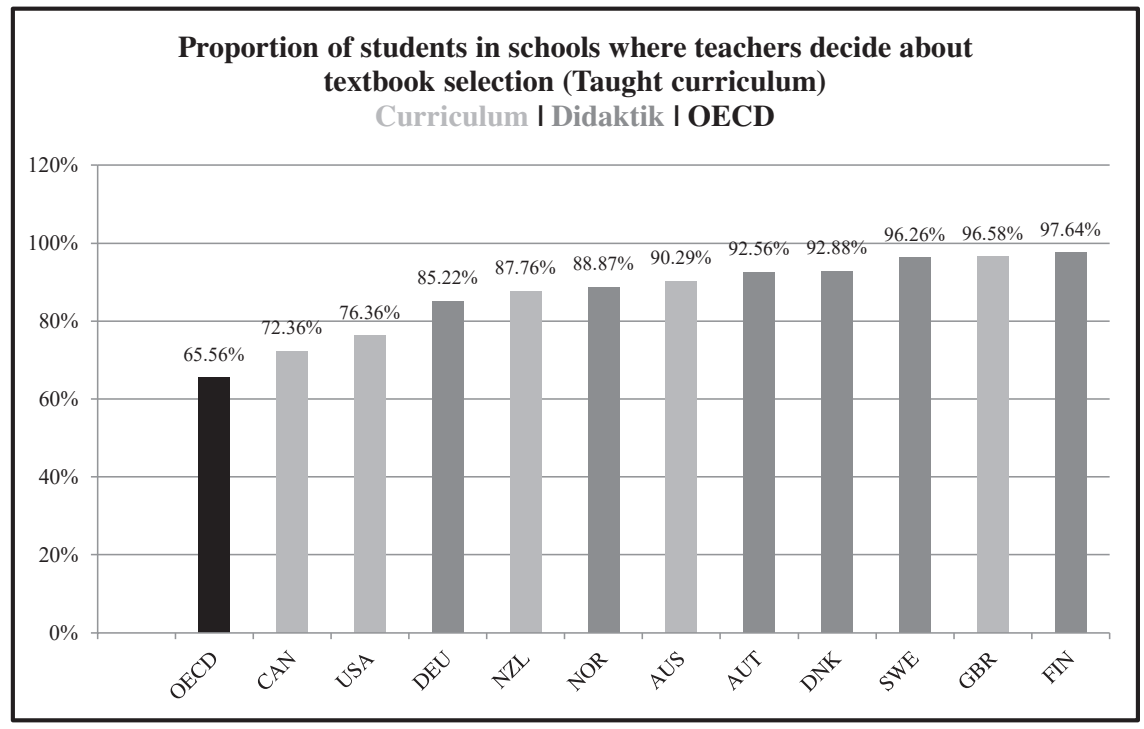

Figure II.2 Taught curriculum (teacher responsibility over textbook selection)

Source: OECD PISA 2015 Datasets

Figure 11.3 shows the proportions of schools where teachers are reported to be responsible for making decisions about student assessment policies in respective countries. As per curriculum-Didaktik framework, the hypothesis was that more schools report teachers to be responsible in Didaktik than in curriculum countries. The graph shows that Germany (83.63 per cent) and Ireland (83.36 per cent) have the highest proportion of schools where teachers are responsible for assessment policies. Denmark has the lowest proportion of schools that have teachers who are responsible for assessment policies, as reported by school principals, with 50.70 per cent. All countries but Denmark and Canada are above the OECD average. A difference-of-proportion test showed that Didaktik countries together had a higher mean than curriculum countries with $\mathrm{z}$ statistic $z=3.49, p<0.001$ indicating that the difference between the two groups was statistically significant.

Tables 11.1 and 11.2 show the results related to the second research question on associations of teacher responsibility items to students' science performance in PISA 2015 in curriculum and Didaktik countries. Only significant results are shown in the two given tables. Among curriculum countries, only Intended measure was significant and positive in the US. Only Taught (negative) and Tested (positive) items were significant in Finland only among Didaktik countries. Even though the proxies for Intended, Taught, and Tested curriculum 


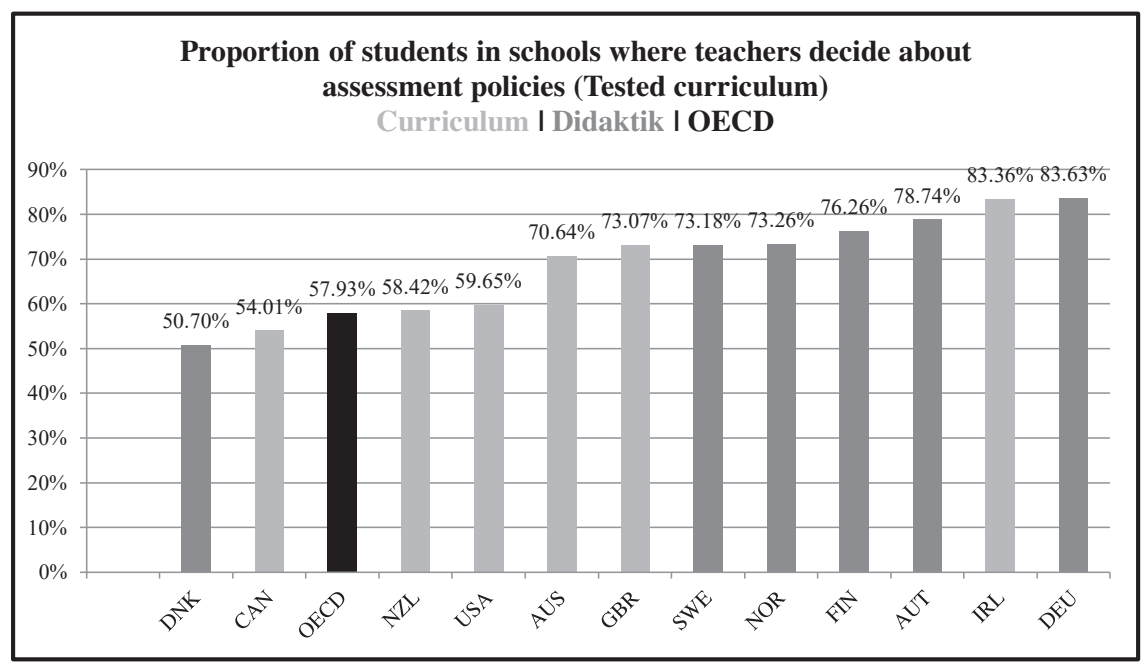

Figure II.3 Tested curriculum (teacher responsibility over assessment policies)

Source: OECD PISA 2015 Datasets

Table II.I Associations of teacher responsibility items and control variables to PISA 2015 science performance (curriculum-full model)

\begin{tabular}{|c|c|c|c|c|c|c|}
\hline & Australia & Canada & United Kingdom & Ireland & New Zealand & United States \\
\hline Intended & 1 & l & l & I & I & 33.33 \\
\hline Taught & l & I & l & l & I & 1 \\
\hline Tested & 1 & 1 & 1 & I & I & 1 \\
\hline SES & 28.81 & 24.33 & 22.21 & 31.31 & 33.25 & 16.37 \\
\hline Girl & -6.25 & -5.21 & I & -11.05 & -8.86 & -11.77 \\
\hline Age & -8.41 & 1 & I & 1 & I & -19.68 \\
\hline Grade & 28.65 & 39.58 & 30.11 & 8.87 & 27.52 & 39.28 \\
\hline $\begin{array}{l}\text { First } \\
\quad \text { immigration }\end{array}$ & I & I & -23.21 & l & -11.29 & -17.68 \\
\hline $\begin{array}{l}\text { Second } \\
\text { immigration }\end{array}$ & I & l & l & l & I & 1 \\
\hline Public school & -32.71 & -28.21 & -41.36 & -21.24 & -60.21 & I \\
\hline
\end{tabular}

Note: Only results significant at $p<0.05, p<0.01$, and $p<0.00$ I shown. If bold, significant at $p<0.001$.

were significant only in three cases, the coefficient was large, indicating that when these factors matter, they do matter significantly in students' science performance in PISA assessment.

The results for control variables across curriculum and Didaktik countries show interesting results, particularly with the negative impact of public school 
Table II.2 Associations of teacher responsibility items and control variables to PISA 2015 science performance (Didaktik-full model)

\begin{tabular}{|c|c|c|c|c|c|c|}
\hline & Austria & Germany & Denmark & Finland & Norway & Sweden \\
\hline Intended & l & I & l & I & l & I \\
\hline Taught & l & l & l & -57.28 & l & l \\
\hline Tested & l & l & I & 38.18 & l & I \\
\hline SES & 9.11 & 9.96 & 23.19 & 29.93 & 29.33 & 28.67 \\
\hline Girl & -24.54 & -24.09 & -11.56 & 14.93 & I & I \\
\hline Age & I & -18.57 & I & I & 17.44 & 1 \\
\hline Grade & 40.29 & 38.81 & 44.77 & 39.02 & 44.60 & 67.79 \\
\hline First immigration & -35.01 & -37.99 & -49.25 & -72.01 & -38.81 & -51.84 \\
\hline Second immigration & -37.04 & -31.97 & -46.78 & -61.09 & -33.08 & -33.75 \\
\hline Public school & I & -56.88 & I & 1 & I & 1 \\
\hline
\end{tabular}

Note: Only results significant at $p<0.05, p<0.01$, and $p<0.00$ I shown. If bold, significant at $p<0.001$.

among curriculum countries, and the negative role of immigration status on science performance among Didaktik countries. This means that students in public schools in curriculum countries have lower performance in science compared to students in private schools, while students of immigrant background perform lower than native students in Didaktik countries. Further, as expected and shown from prior studies, the SES is strongly and positively associated with students' science performance in all countries in the sample, meaning that students that come from more affluent families perform higher than those that come from less affluent families. The results also show that students who are in a higher grade at the time of PISA test perform better than students who are in a lower grade. The gender variable also shows interesting patterns across countries by being strong and negative in almost all countries but Finland where it is strong and positive. This means that girls score lower than boys in PISA science test in all countries in the sample where the variable is statistically significant, with the exception of Finland, where girls outperform boys. Lastly, students' age does not seem to be strongly associated with students' science performance in the given statistical models and controlling for the listed variables.

Overall, the results of HLM models are in line with prior work and hypothesis that teacher responsibility proxies are statistically significant only in a few cases.

\section{Discussion and conclusions}

The results of the study point towards a Didaktik-curriculum continuum, rather than a strict dichotomy as suggested by the theory, however the countries tend to stick together within either Didaktik or curriculum grouping. Because all the countries in the sample have a relatively high number of students in schools where teachers are responsible for all three variables of interest, a practical 
convergence is observed that seems to go against the clear theoretical divide between curriculum and Didaktik as theorised in the literature. Still, the findings from the first research question point to statistically significant differences in variation between Didaktik and curriculum in Teacher Responsibility over Intended, Taught, and Tested curriculum - in all three cases, teacher responsibility is higher among teachers in schools in Didaktik than in curriculum sample. On average, teacher responsibility among all countries in the sample is higher than the OECD average, with a few exceptions, indicating that overall teachers in schools in both educational traditions have high responsibility, as reported by the school principals through the PISA study.

Regarding the second research question, which tested whether teacher responsibility items make a difference in students' science performance as measured in PISA 2015, the results are discouraging overall, as significant associations were identified in three cases in two countries only - in the US and Finland. The lack of significant results may be an effect of the global education reform movement in the Western world, primarily that has made education policy and practices more uniform across countries, a phenomenon labelled as institutional isomorphism (Baker and LeTendre, 2005). Nevertheless, the evidence for continued variation pertaining to the first research question indicates that divisions between Didaktik and curriculum traditions still persist and that traditions on which education systems are built upon continue to affect educational practices within countries. Further research could potentially focus on how teacher responsibility is shared with other stakeholders such as school leaders and parent communities within the school context, where usually a broad array of interests and responsibilities have to be negotiated, shared, and executed to create and maintain learning environments that enhance students' performance and achievement in and out of schools.

\section{References}

Baker, D. and LeTendre, G. K. (2005). National differences, global similarities: World culture and the future of schooling. Redwood City, CA: Stanford University Press.

Corcoran, T. B. (1995). Transforming professional development for teachers: A guide for state policymakers. Washington, DC: National Governors Association.

Deng, Z. and Luke, A. (2008). Subject matter: Defining and theorizing school subjects. In: F. M. Connelly, M. F. He and J. Phillion, eds., The Sage handbook of curriculum and instruction. Thousand Oaks, CA: Sage, pp. 66-87.

Frostenson, M. (2012). Lärarnas avprofessionalisering och autonomins mångtydighet [The deprofessionalisation of teachers and the ambiguity of autonomy]. Nordiske Organisasjonsstudier, 2, pp. 49-78.

Gundem, B. B. and Hopmann, S. (1998). Didaktik and/or curriculum. New York: Peter Lang. Hopmann, S. (2007). Restrained teaching: The common core of Didaktik. European Educational Research Journal, 6(2), pp. 109-124.

Hopmann, S. (2015). 'Didaktik meets curriculum' revisited: Historical encounters, systematic experience, empirical limits. Nordic Journal of Studies in Educational Policy, 1(1), pp. 14-21. https://doi.org/10.3402/nstep.v1.27007. 
House, R. J., Hanges, P. J., Javidan, M., Dorfman, P. W. and Gupta, V. (2004). Culture, leadership, and organizations: The GLOBE study of 62 cultures. Thousand Oaks, CA: Sage.

Klette, K. (2007). Trends in research on teaching and learning in schools: Didactics meets classroom studies. European Educational Research Journal, 6(2), pp. 147-160.

Kliebard, H. M. (2004). The struggle for the American curriculum, 1893-1958. New York: Routledge.

OECD (Organisation for Economic Co-operation and Development). (2009). PISA 2009 assessment framework: Key competencies in reading, mathematics and science. Paris: OECD.

Raudenbush, S. W. and Bryk, A. S. (2002). Hierarchical linear models: Applications and data analysis methods. Thousand Oaks, CA: Sage.

Schiro, M. S. (2013). Curriculum theory: Conflicting visions and enduring concerns. Thousand Oaks, CA: Sage.

Schubert, W. H. (2008). Curriculum inquiry. In: F. M. Connelly, M. F. He and J. Phillion, eds., The Sage handbook of curriculum and instruction. Thousand Oaks, CA: Sage, pp. 399-419.

Tahirsylaj, A. (2017). Curriculum field in the making: Influences that led to social efficiency as dominant curriculum ideology in progressive era in the U.S. European Journal of Curriculum Studies, 4(1), pp. 618-628. Available at: http://pages.ie.uminho.pt/ejcs/index.php/ ejcs/article/view/156 [Accessed 22 May 2020].

Tahirsylaj, A. (2019). Teacher autonomy and responsibility variation and association with student performance in Didaktik and curriculum traditions. Journal of Curriculum Studies, 51(2), pp. 162-184. https://doi.org/10.1080/00220272.2018.1535667.

Tahirsylaj, A., Brezicha, K. and Ikoma, S. (2015). Unpacking teacher differences in Didaktik and curriculum traditions: Trends from TIMSS 2003, 2007, and 2011. In: G. K. LeTendre and A. W. Wiseman, eds., Promoting and sustaining a quality teacher workforce (International perspectives on education and society). Bingley: Emerald Group Publishing Limited, pp. 145195. https://doi.org/10.1108/S1479-367920140000027008.

Tahirsylaj, A., Niebert, K. and Duschl, R. (2015). Curriculum and Didaktik in 21st century: Still divergent or converging? European Journal of Curriculum Studies, 2(2), pp. 262-281. Available at: http://pages.ie.uminho.pt/ejcs/index.php/ejcs/article/view/91 [Accessed 22 May 2020].

Wermke, W. and Höstfält, G. (2014). Contextualizing teacher autonomy in time and space: A model for comparing various forms of governing the teaching profession. Journal of Curriculum Studies, 46(1), pp. 58-80.

Westbury, I. (2000). Teaching as a reflective practice: What might Didaktik teach curriculum? In I. Westbury, S. Hopmann and K. Riquarts, eds., Teaching as a reflective practice: The German Didaktik tradition. Mahwah, NJ: Lawrence Erlbaum Associates, pp. 15-39.

Zhang, L., Khan, G. and Tahirsylaj, A. (2015). Student performance, school differentiation, and world cultures: Evidence from PISA 2009. International Journal of Educational Development, 42, pp. 43-53. https://doi.org/10.1016/j.ijedudev.2015.02.013. 